\section{Nível do conhecimento da equipe de enfermagem com relação aos cuidados paliativos}

\author{
Cardozo, Elisangela de Oliveira \\ Hospital IPO/ PPGBIOÉTICA-PUCPR. e-mail: \\ elisakrill@hotmail.com
}

\section{Cardozo, Cassiane Caroline de Oliveira \\ Acadêmica Biologia - PUCPR}

Chiesa, Daniella de Paula

Mestre em Bioética PPGBIOÉTICA-PUCPR

\section{Souza, Waldir}

Prof. Doutor PPGBIOÉTICA-PUCPR

PALAVRAS-CHAVE: Cuidados Paliativos, Enfermagem, Envelhecimento populacional.

Introdução: Dados do mundo inteiro revelam que a expectativa de vida das pessoas vem aumentando gradativamente inclusive no Brasil. $\mathrm{O}$ fato é que aumento de expectativa de vida não necessariamente quer dizer qualidade de vida. O homem é um ser finito, assim a morte deve ser compreendida como um processo natural, parte da vida, e a qualidade de vida deveria ser o principal objetivo clínico. Nesta perspectiva os Cuidados Paliativos (CP) trazem uma abordagem mais específica para melhoria da qualidade de vida de pacientes e familiares que enfrentem uma doença ameaçadora da vida, através da prevenção e do alívio do sofrimento, identificação precoce e tratamento impecável da dor e de outros problemas, físicos, psicossociais e espirituais. Objetivo: Identificar o nível de conhecimento dos profissionais da área de enfermagem com relação aos CP. Metodologia: Pesquisa descritiva quaslitativa, com utilização de dois questionários com 10 questões cada, que visam demonstrar o nível de escolaridade, facilidade de acesso à informação, idade, tempo de atuação na área e o nível de conhecimento específico em CP. A pesquisa foi desenvolvida em duas instituições privadas localizadas na cidade de Curitiba. Participaram espontaneamente do estudo 75 profissionais da área de enfermagem maiores de 18 anos, ou seja, técnicos e auxiliares de enfermagem e enfermeiros. Dos 75 formulários recebidos, 6 deles foram desconsiderados por não conter todos os campos preenchidos ou por estarem ilegíveis. A amostra final contou com 69 formulários os quais continham todas as informações completas. O projeto foi aprovado pelo CEP do Hospital IPO sob o n ${ }^{\circ}$ 171/2017. Resultados: Dos 69 questionários avaliados apenas 11 tinham respostas conclusivas, ou seja, 58 profissionais não tinham o conhecimento adequado sobre o tema. Com relação à indicação de $\mathrm{CP} 53$ profissionais informaram que cuidados paliativos deveriam ser aplicados aos pacientes no fim de vida e 47 deles afirmaram que se tratava de cuidados para os pacientes com câncer já em estado muito avançado e sem chance de cura. Todas as demais questões tabuladas forneceram igual resultado e demonstraram a falta de preparo e de conhecimento dos profissionais da área de enfermagem com relação aos $\mathrm{CP}$. Discussão: $\mathrm{O}$ resultado obtido corrobora as afirmações de vários autores que demonstram que apesar da Medicina Paliativa ser reconhecida pelo Conselho Federal de Medicina desde 2010 ainda impera o desconhecimento sobre o tema. Apesar da Academia Nacional de Cuidados Paliativos possuir manuais de CP e alguns Corens do país emitirem pareceres técnicos sobre o assunto a assimilação do real objetivo dos $\mathrm{CP}$ ainda se mostra ineficiente. Conclusão: Os cuidados paliativos devem ser oferecidos necessariamente por uma equipe multi e interdisciplinar, ou seja, são vários os profissionais que devem obrigatoriamente compor esta equipe, porém é importante ressaltar que apesar da equipe multidisciplinar o enfermeiro é um dos profissionais que tem maior contato e lida diariamente com o paciente e seus familiares, neste caso é importantíssima à avaliação do conhecimento e de preparo deste profissional para a prática do atendimento diário aos pacientes, portanto a disseminação desse conhecimento se faz indiscutivelmente urgente e necessária.

\section{REFERÊNCIAS}

[1] ACADEMIA NACIONAL DE CUIDADOS PALIATIVOS. Ricardo Tavares de Carvalho e Henrique Afonseca Parsons (organizadores). Manual de cuidado paliativos ANCP. Revisão Ampliada. 2 ${ }^{\mathrm{a}}$. ed, 2012

[2] CONSELHO FEDERAL DE MEDICINA. Resolução CFM 1.973, que define a Medicina Paliativa como área de atuação. Brasilia, 2011. Disponível em: http://www.portalmedico.org.br/resolucoes/cfm/2011/1 973 2011.htm.

a. Acesso em: 22 ago. 2018.

[3] Organização Mundial da Saúde. Relatório Mundial da Saúde (2010). FINANCIAMENTO DOS SISTEMAS DE SAÚDE O caminho para a cobertura universal. Disponível em http://www.who.int/eportuguese/publications/WHR201 0.pdf. Acesso em 26 ago.2018.

[4] PESSINI, L. Cuidados paliativos: alguns aspectos conceituais, biográficos e éticos. Prática Hospitalar, 2005; (41), p. 107-112 